\title{
DERIVAÇÃO BÍLEO-DIGESTIVA COM O DUCTO DO SEGMENTO III DO FÍGADO EM OBSTRUÇÃO HILAR MALIGNA
}

\author{
SEGMENT III CHOLANGIOJEJUNOSTOMY FOR MALIGNANT HEPATIC HILUS \\ OBSTRUCTION
}

\section{João Eduardo Nicoluzzi, TCBC-PR ${ }^{1}$; Gustavo Marquesini Paul²; Pedro Ernesto Caron, TCBC-PR ${ }^{3}$}

\section{INTRODUÇÃO}

As estenoses neoplásicas da árvore biliar extra-hepática podem ser devidas a colangiocarcinomas localizados na confluência dos ductos hepáticos direito e esquerdo ${ }^{1}$, tumores de "Klastskin", ou devido a neoplasias secundárias.

A cirurgia radical, com intenção curativa, é possível em 10 a $50 \%$ dos casos, dependendo do estádio do tumor na época do diagnóstico e da habilidade do cirurgião $0^{2,3}$. As contra-indicações para a cirurgia radical são: comprometimento tumoral além da confluência dos ductos hepáticos secundários, invasão de ramos portais e da artéria hepática comum, metástases à distância e a condição clínica precária ${ }^{3}$. Por isso, as indicações para tratamento paliativo são freqüentes, sendo que nos últimos 10 anos a maioria destes pacientes com icterícia obstrutiva são tratados principalmente por métodos paliativos micro-invasivos, resultado do constante refinamento endoscópico e radiográfico.

Apesar desta evolução, a derivação bíleo-digestiva utilizando-se o ducto biliar do segmento III do fígado, apresenta papel e indicação precisa no manejo desta população de doentes. O objetivo deste trabalho é relatar um caso bem sucedido de paciente com tumor irressecável de via biliar tratado por derivação bíleo-digestiva utilizando-se o ducto do segmento III.

\section{RELATO DO CASO}

JDC, 44 anos, branco, sexo masculino, com quadro de dor abdominal, emagrecimento, colestase e prurido intenso, bilirrubina total (BT): 17,6; bilirrubina direta (BD): 13,3; bilirrubina indireta (BI): 4,3. No exame tomográfico do abdômen foi evidenciada tumoração no hilo hepático com dilatação significativa da via biliar intra-hepática, sem evidência de metástases à distância.

À exploração cirúrgica evidenciamos a presença de tumoração irressecável na via biliar principal, com linfonodomegalia local peri-coledociana importante, sem comprometimento linfonodal celíaco ou inter aórtico-cava. O resultado da biópsia por congelação de linfonodo hilar demonstrou infiltração tumoral maligna.
A dissecção do parênquima hepático foi realizada à esquerda do ligamento redondo para acessar o ducto hepático do segmento III.

Feita anastomose entre o ducto do segmento III com alça jejunal em omega (figura 1) com pontos separados de PDS 5.0 e na sequência drenagem da cavidade com dreno laminar de Penrose.

O paciente apresentou boa evolução e teve alta hospitalar no $4^{\circ}$ pós-operatório. No seguimento de dois meses paciente sem queixas, ganho ponderal de $3 \mathrm{~kg}$, icterícia discreta e parâmetros laboratoriais de BT: 2,8; BD: 2,2 e BI: 0,6.

\section{DISCUSSÃO}

A quase totalidade dos pacientes ictéricos por tumor que atinge o colédoco e o hilo hepático necessita de algum tipo de tratamento paliativo. Raros são os casos passíveis de tratamento curativo. Estes pacientes necessitam de drenagem biliar que permita o restabelecimento normal da função hepática e diminua a icterícia e o prurido.

A drenagem biliar externa, como a técnica de Praderi, permite regressão parcial da icterícia, porém priva o organismo de sais biliares além de líquidos e eletrólitos. Em geral

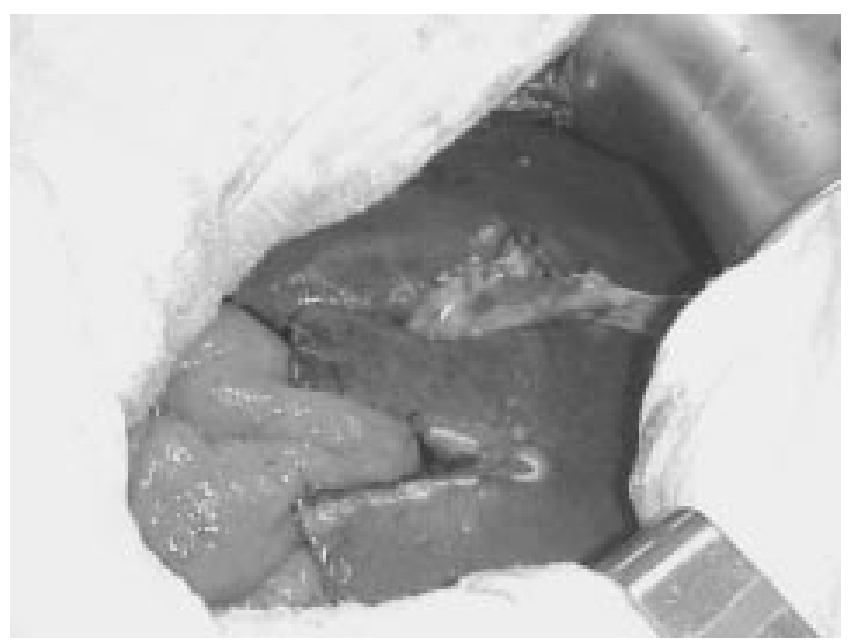

Figura 1 - Anastomose bíleo-digestiva entre segmento III e alça jejunal em ômega.

\footnotetext{
1. Coordenador do Programa de Transplante Hepático e Pancreático do Hospital Angelina Caron (HAC); Especialista em Cirurgia Hepato-Biliar pela Universidade Paris XI, Hôpital Paul Brousse, Serviço do Pr H. Bismuth, Paris; Doutor em Cirurgia pela UFPR; Professor Adjunto da PUC-PR.

2. Residente do Serviço de Cirurgia-geral do HAC.

3. Chefe do Serviço de Cirurgia-Geral do HAC; Mestre em Cirurgia PUC-PR 
permite sobrevida com má qualidade de vida por algumas semanas.

A drenagem biliar interna através da colocação da prótese biliar via endoscópica, permite a regressão completa da icterícia e do prurido, sem deprimir o organismo de sais biliares. Esta é a terapia preferida atualmente pele sua aparente simplicidade de execução e pela possibilidade de se evitar os riscos de uma cirurgia. Porém vale a pena lembrar que o percentual de sucesso varia para neoplasia da bifurcação entre $75 \%$ à $85 \%$, com mortalidade até o $30^{\circ}$ dia entre $20-25 \%$ e a oclusão da prótese ocorre em média após 3 meses ${ }^{4}$.

Menos utilizadas as drenagens internas-externas apresentam as vantagens das drenagens internas com a possibilidade de lavagem pela parte exteriorizada do tubo, com benefício de manter a prótese pérvia por períodos mais longos.

Apesar das próteses serem o tratamento mais comumente utilizado nesta população de pacientes, o período de sobrevida e a qualidade de vida destes pacientes é inferior à obtida com a cirurgia ${ }^{5}$.
A derivação bíleo-digestiva estaria indicada em casos nos quais se possa esperar uma paliação, a médio e longo prazos, superior à oferecida pelas próteses sem o inconveniente de colangites precoces e de manutenção quotidiana. Também nos casos de achado cirúrgico inesperado de tumor irressecável, em pacientes francamente ictéricos nos quais parece injustificável renunciar à paliação cirúrgica imediata, com risco e tempo cirúrgicos moderados, e encaminhá-lo à posterior paliação mini-invasiva ${ }^{4,5}$.

A escolha do ducto do segmento III deve-se em parte pela vantagem de manter-se o mais distante possível do tumor, do fato que o pedículo deste segmento ser muito constante e pela relativa facilidade de expô-10 ${ }^{5}$.

Portanto parece útil a opção de drenagem cirúrgica paliativa nos pacientes com condição clínica não excessivamente comprometida, reservando-se os métodos endoscópicos aos pacientes em condição clínica mais grave com baixa expectativa de vida, que não tolerariam uma agressão cirúrgica.

\begin{abstract}
Cholangiocarcinoma of the hepatic hilum is a seldom curable lesion. Those patients are often managed with prostheses. Cholangiojejunostomy on the third segment of the liver seems to offer effective biliary drainage with better quality of life compared to other forms of palliation. The aim of this paper is to report a successful case of a patient with irressectable biliary tumor submitted to a surgical biliary drainage (Rev. Col. Bras. Cir. 2006; 33(1): 60-61).
\end{abstract}

Key words: Cholangiocarcinoma; Liver neoplasms; Liver.

\section{REFERÊNCIAS}

1. Klatskin G. Adenocarcinoma of the hepatic duct at its bifurcation within the porta hepatis: an unusual tumor with distinctive clinical and pathological features. Am J Med. 1965; 38:241-56.

2. Traynor O, Castaing D, Bismuth H. Left intrahepatic cholangioenteric anastomosis (round ligament approach): an effective palliative treatment for hilar cancers. Br J Surg. 1987; 74(10): 952-4.

3. Gazzaniga Gm, Filauro M, Bagarolo C, et al. Neoplasm of the hepatic hilum: the role of resection. Hepatogastroenterol. 1993; 40(3):244-8.
4. Susuki S, Kurachi K, Yokoi Y, et al. Intrahepatic cholangiojejunostomy for unresectable malignant biliary tumors with obstructive jaundice. J Hepatobiliary Pancreat Surg. 2001; 8(2):124-9.

5. Confalonieri F, Ballerini A. Colangiodigiunostomia palliativa sul dotto del $3^{\circ}$ segmento epatico. La nostra esperienza. Minerva Chir. 1998; 53(9):709-14.

Endereço para correspondência:

Dr. João Eduardo Nicoluzzi

Rua: Santo Amaro, 118 - Água Verde.

80620-330 Curitiba-PR

E-mail:jenicoluzz@yahoo.com 